\title{
Family study of lipid and purine levels in gout patients
}

\author{
L. GAIL DARLINGTON, ${ }^{1} \mathrm{~J} . \mathrm{SLACK}^{2}$ AND J. T. SCOTT ${ }^{3}$
}

From ${ }^{1}$ Epsom Rheumatology Unit, Epsom District Hospital, Epsom, Surrey; the ${ }^{2}$ MRC Clinical Genetics Unit, Institute of Child Health, London; and ${ }^{3}$ Charing Cross Hospital and Kennedy Institute of Rheumatology, London

SUMMARY A family study was performed to determine whether the hypertriglyceridaemia associated with gout is present in families of gout patients or due to the life style of the patient himself. The study revealed the expected hypertriglyceridaemia in gout patients; this was reflected by elevated serum levels of prebetalipoproteins and with reduction in the proportion of beta-lipoprotein. None of these abnormalities were seen in the first-degree relatives. Furthermore, the proportion of high-density lipoproteins was not significantly raised in gout patients.

To determine whether the hypertriglyceridaemia of gout patients occurs in their families or is simply the result of the life style of these obese, often alcoholdrinking patients who frequently originate from higher social classes ${ }^{1}$ a family study was designed to measure lipid and uric acid levels in the blood of gout patients and their first-degree relatives and to compare them with those found in controls of the same age and sex.

\section{Patients and methods}

Pedigrees were constructed for 169 male and 11 female primary gout patients with details of age and whereabouts of all living, first-degree relatives. The patients had been diagnosed by generally accepted clinical criteria; many of them were receiving treatment for hyperuricaemia at the time of the study. Fasting blood samples were analysed to determine lipid and uric acid levels. Cholesterol was measured by a revision of the Schoenheimer-Sperry method for cholesterol determination, ${ }^{2}$ triglycerides by a micromethod for direct determination, ${ }^{3}$ and electrophoretic separation of lipoproteins was performed in agarose gel by the method of Noble. ${ }^{4}$ Plasma urate was measured by direct ferric reduction or by absorbance change on oxidation of urate with alkaline ferricyanide. $^{5}$

Owing to regional and ethnic variations in lipid concentrations ${ }^{6}$ results were compared with those

Accepted for publication 15 April 1981.

Correspondence to Dr L. Gail Darlington, Epsom District Hospital, Dorking Road, Epsom, Surrey KT18 7EG. obtained by the same laboratory from 2388 control subjects of known age and sex from the same geographical area and ethnic background as the gout group, that is, from a working population in northwest London.?

\section{Results}

Lipid and uric acid data for gout patients, first-degree relatives, and expected values for controls at the same mean age are given in traditional units in Tables $1 \mathrm{a}$ and $1 \mathrm{~b}$.

The means and standard deviations of variables from gouty index patients and relatives when compared with controls are also expressed in standard

Table 1a Lipid and uric acid data from male gout patients and male first-degree relatives

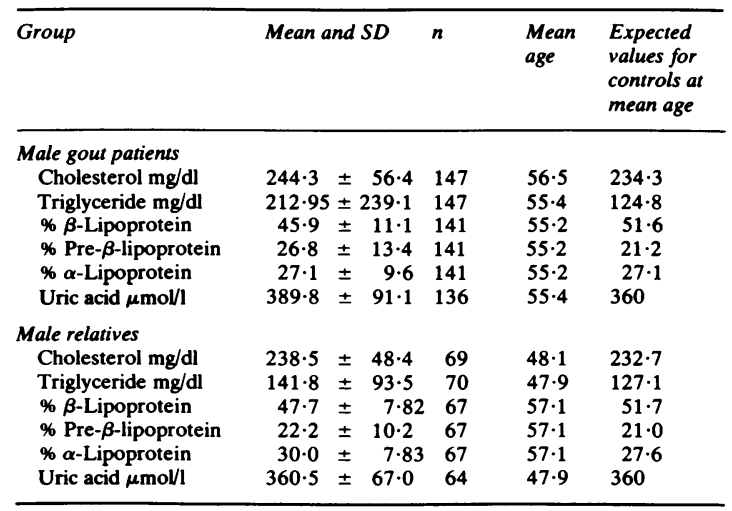


Table 1b Lipid and uric acid data from female gout patients and female first-degree relatives

\begin{tabular}{|c|c|c|c|c|}
\hline Group & Mean and $S D$ & $n$ & $\begin{array}{l}\text { Mean } \\
\text { age }\end{array}$ & $\begin{array}{l}\text { Expected } \\
\text { values for } \\
\text { controls at } \\
\text { mean age }\end{array}$ \\
\hline \multicolumn{5}{|l|}{ Female gout patients } \\
\hline Cholesterol mg/dl & $270 \cdot 5 \pm 91 \cdot 0$ & 4 & $57 \cdot 3$ & $254 \cdot 1$ \\
\hline Triglycerides $\mathrm{mg} / \mathrm{dl}$ & $133 \cdot 8 \pm 51 \cdot 0$ & 4 & $57 \cdot 3$ & $111 \cdot 7$ \\
\hline$\% \beta$-Lipoprotein & $47 \cdot 1 \pm$ & 4 & $57 \cdot 3$ & $50 \cdot 8$ \\
\hline$\%$ Pre- $\beta$-lipoprotein & $20 \cdot 0 \pm$ & 4 & $57 \cdot 3$ & $17 \cdot 9$ \\
\hline$\% \alpha$-Lipoprotein & $32.9 \pm 5 \cdot 21$ & 4 & $57 \cdot 3$ & $32 \cdot 5$ \\
\hline Uric acid $\mu \mathrm{mol} / \mathrm{l}$ & $381 \cdot 1 \pm 121 \cdot 6$ & 4 & $57 \cdot 3$ & 300 \\
\hline \multicolumn{5}{|l|}{ Female relatives } \\
\hline Cholesterol mg/dl & $241 \cdot 8 \pm$ & 102 & $47 \cdot 8$ & $231 \cdot 6$ \\
\hline Triglycerides $\mathrm{mg} / \mathrm{dl}$ & $96.4 \pm$ & 103 & $47 \cdot 8$ & $97 \cdot 5$ \\
\hline$\% \boldsymbol{\beta}$-Lipoprotein & $48 \cdot 7 \pm$ & 99 & $46 \cdot 7$ & $50 \cdot 2$ \\
\hline$\%$ Pre- $\beta$-lipoprotein & $15 \cdot 3 \pm$ & 99 & $47 \cdot 3$ & $17 \cdot 1$ \\
\hline$\% \alpha$-Lipoprotein & $36 \cdot 2 \pm$ & 99 & $47 \cdot 3$ & $32 \cdot 4$ \\
\hline Uric acid $\mu \mathrm{mol} / \mathrm{l}$ & $291.0 \pm 69.0$ & 101 & $48 \cdot 0$ & 270 \\
\hline
\end{tabular}

SI conversion $=$ cholesterol $\mathrm{mmol} / \mathrm{l}=\mathrm{mg} / \mathrm{dl} \times 0.0259$.

Triglycerides $\mathrm{mmol} / \mathrm{l}=\mathrm{mg} / \mathrm{dl} \times 0.0113$.

deviation units in Table 2 to eliminate the variables of age and sex. The statistical significance of differences between data from gout patients, relatives, and controls is indicated. Table 2 shows that triglyceride levels in gout patients were found to be significantly higher than in controls $(\mathrm{p}<0 \cdot 001)$. These changes were, predictably, reflected by changes in the proportion of pre- $\beta$-lipoprotein, which was also significantly higher in gout patients than in controls $(\mathrm{p}<0.001)$. There was a significant reduction in the proportion of $\beta$-lipoprotein in gout patients when compared with controls $(\mathrm{p}<0.001)$.

Table 3 shows that triglyceride and pre- $\beta$-lipoprotein levels in gout patients were significantly higher than in relatives $(\mathrm{p}<0.001)$ with a significant reduction in the proportion of $\beta$-lipoprotein $(0.01>p>0.001)$.

Table 3 shows a small but significant reduction in the proportion of $\beta$-lipoprotein in relatives when

Table 2 Differences in mean values of variables studied between index patients and controls and first-degree relatives and controls, expressed in standard deviation units

\begin{tabular}{lllll}
\hline Variable & $\begin{array}{l}\text { Index patients } \\
\text { compared with } \\
\text { controls }\end{array}$ & $\begin{array}{l}\text { No. of } \\
\text { subjects }\end{array}$ & $\begin{array}{l}\text { First-degree } \\
\text { relatives } \\
\text { compared with } \\
\text { controls }\end{array}$ & $\begin{array}{l}\text { No. of } \\
\text { subjects }\end{array}$ \\
\hline Cholesterol & $+0 \cdot 20 \pm 1 \cdot 15$ & 143 & $+0.25 \pm 1 \cdot 12^{*}$ & 165 \\
Triglycerides & $+0.60 \pm 1 \cdot 28^{* * *} 143$ & $-0.16 \pm 1 \cdot 18$ & 165 \\
$\% \beta$-Lipoprotein & $-0.78 \pm 1 \cdot 49^{* * *} 142$ & $-0 \cdot 34 \pm 1 \cdot 18^{* * *}$ & 162 \\
\% Pre- $\beta$-lipoprotein & $+0.71 \pm 1 \cdot 55^{* * *} 142$ & $-0.04 \pm 1 \cdot 07$ & 161 \\
$\% \alpha$-Lipoprotein & $-0.07 \pm 1 \cdot 32$ & 141 & $+0.27 \pm 1 \cdot 24^{*}$ & 162 \\
Uric acid & $+0.61 \pm 1 \cdot 44^{* * *} 140$ & $+0.05 \pm 1 \cdot 28$ & 159 \\
\hline
\end{tabular}

${ }^{*} 0 \cdot 05>p>0 \cdot 01 .{ }^{* *} 0 \cdot 01>p>0 \cdot 001 .{ }^{* * *} p=<0.001$.
Table 3 Lipid and uric acid results from family study

\begin{tabular}{llll}
\hline & $\begin{array}{l}\text { Difference } \\
\text { between index } \\
\text { patients and } \\
\text { controls }\end{array}$ & $\begin{array}{l}\text { Difference } \\
\text { between index } \\
\text { patients and } \\
\text { 1st-degree } \\
\text { relatives }\end{array}$ & $\begin{array}{l}\text { Difference } \\
\text { between } \\
\text { 1st-degree } \\
\text { relatives and } \\
\text { controls }\end{array}$ \\
\cline { 2 - 4 } & Significance & Significance & Significance \\
\hline Cholesterol & NS & NS & $*$ \\
Triclycerides & $* * *$ & $* * *$ & NS \\
\% of $\beta$-lipoprotein & $* * *$ & $* *$ & $* *$ \\
$\%$ of pre- $\beta$-lipoprotein & $* * *$ & $* * *$ & NS \\
\% of $\alpha$-lipoprotein & NS & $*$ & NS \\
Uric acid in males & $* * *$ & $* * *$ & NS \\
Uric acid in females & NS & $*$ & \\
\hline
\end{tabular}

NS $=$ not significant. ${ }^{*} 0.05>p>0.01 .{ }^{* *} 0.01>p>0.001 .{ }^{* * *} p=<0.001$.

compared with control subjects $(0.01>p>0.001)$ but no difference in triglycerides or pre- $\beta$-lipoprotein levels.

Table 3 also shows a marginal increase in the proportion of $\alpha$-lipoprotein in relatives when compared with both gout patients and controls $(0 \cdot 05>p>0 \cdot 01)$, but there was no significant difference between the $\alpha$-lipoprotein proportions in gout patients and controls. There was no significant difference between cholesterol levels in gout patients and controls or between gout patients and relatives, but both Tables 2 and 3 show that there was a marginal increase in cholesterol levels in relatives when compared with controls $(0.05>p>0 \cdot 01)$.

As shown in Table 3, uric acid levels in male, gouty index patients were significantly higher than in controls or relatives $(p<0.001)$, despite the fact that many of them were on urate-lowering drugs. Separate analysis of female index patients must be assessed with caution in view of the small numbers concerned. Table 2 shows that the mean uric acid level in relatives was slightly greater than in controls, but this difference was very small and did not approaich the significant elevation found in the study of Hauge and Harvald. ${ }^{8}$

The families of 35 gout patients who were found to have lipid levels (triglyceride and/or cholesterol) above the 95th centile were assessed to determine whether they constituted a particular subgroup in the family study.

First-degree relatives of hyperlipidaemic, gouty index patients had raised cholesterol levels when compared with controls (males $0.05>p>0.025$; females $0.02>p>0 \cdot 01$ ). There were no elevations in triglyceride levels among these relatives.

Weights were measured in gout patients, relatives, and controls. There were too few female gout patients for analysis, but the weight data presented in Tables 4 and 5 were analysed and showed that male, gout patients were significantly heavier than male 
Table 4 Weight data from index patients and relatives

\begin{tabular}{lll}
\hline & Range in $k g$ & Mean weight in $\mathbf{k g}$ \\
\hline Male index patients & $57 \cdot 1-126 \cdot 4$ & $82 \cdot 5$ \\
Female index patients & $58 \cdot 4-80 \cdot 0$ & $67 \cdot 1$ \\
Male relatives & $50 \cdot 9-103 \cdot 2$ & $76 \cdot 0$ \\
Female relatives & $37 \cdot 3-105 \cdot 0$ & $61 \cdot 5$ \\
\hline
\end{tabular}

Table 5 Weight data from controls

\begin{tabular}{lclc}
\hline & Number & Mean weight in $\mathrm{kg}$ & SD in $\mathrm{kg}$ \\
\hline Male & 1645 & 75.01 & $10 \cdot 34$ \\
Female & 743 & 62.98 & $9 \cdot 35$ \\
Total & 2388 & 71.26 & 10.04 \\
\hline
\end{tabular}

relatives and controls $(p=<0 \cdot 001)$. The mean weight of hyperlipidaemic male gout patients was not, however, significantly heavier than the mean of the whole gouty group. This obesity may well be associated with hypertriglyceridaemia in certain male subjects and in raised triglyceride levels in the whole male gout population.

The alcohol intake of the hyperlipidaemic group varied widely, emphasising that alcohol is only one factor in inducing hyperlipidaemia but is doubtless significant in some cases.

\section{Discussion}

Many authors have noted an association between hypertriglyceridaemia and gout. For example, Darlington and $\mathrm{Scott}^{9}$ found significant hypertriglyceridaemia in primary gout patients when compared with matched controls $(0.01>p>0 \cdot 001)$. Berkowitz ${ }^{10}$ and Frank ${ }^{11}$ found raised triglyceride levels in $52 \%$ and $84 \%$ of gout patients repectively, but this association was not seen in patients with symptomless hyperuricaemia. ${ }^{11}$

In 1973 Mielants et al. ${ }^{12}$ found an increase in the proportion of pre- $\beta$-lipoproteins and a reduction in the proportions of $\alpha$ - and $\beta$-lipoproteins in gout patients. Emmerson and Knowles ${ }^{13}$ demonstrated hypertriglyceridaemia in primary gout patients persisting after correction for body weight, and Darlington and $\mathrm{Scott}^{9}$ also described gout and hypertriglyceridaemia independent of obesity.

In 1974 Gibson and Grahame ${ }^{14}$ suggested that obesity, alcohol, or both were the main causes of hypertriglyceridaemia in gout. Gibson et al. ${ }^{15}$ later showed significant reductions in triglycerides in gout patients following reduction of either alcohol intake or weight, but Darlington and Scott, ${ }^{16}$ although observing some reduction in triglycerides after alcohol abstention, did not find that this achieved statistical significance.
Elkeles and Chalmers ${ }^{17}$ raised triglyceride concentrations by infusion of fat but did not demonstrate an effect on plasma uric acid from this elevation of triglyceride. Gibson et al. ${ }^{15}$ also used the Intralipid tolerance test and similarly failed to demonstrate any effect either of triglyceride on uric acid levels or of hyperuricaemia on triglyceride removal.

The hypercholesterolaemia in first-degree relatives of hyperlipidaemic gouty index patients is best explained by polygenic inheritance in the same way as first-degree relatives of tall index patients tend to be taller than average. Since the hyperlipidaemia was a hypercholesterolaemia (and not a hypertriglyceridaemia such as occurs in association with gout) it was probably a finding which is unrelated to hyperuricaemia or gout itself.

Unaffected relatives of gout patients have been reported to show an increased serum level of uric acid, which is thought to be determined by polygenetic factors. ${ }^{8}$

The results of this family study reveal hyperpre- $\beta$ lipoproteinaemia in gout patients as a whole with reduction in $\beta$-lipoprotein. These abnormalities were not seen in first-degree relatives, suggesting that the hypertriglyceridaemia associated with gout is not present in the families of gout patients but is rather due to factors in the life style of the patients.

L.G.D. gratefully acknowledges the support from a Trustees' Research Fellowship from Charing Cross Hospital, London, at the time when this study was performed.

\section{References}

${ }^{1}$ Grahame R, Scott J T. Clinical survey of 354 patients with gout. Ann Rheum Dis 1970; 29: 461-8.

${ }^{2}$ Sperry W M, Webb M. A revision of the Schoenheimer-Sperry method for cholesterol determination. J Biol Chem 1950; 187: 97-106.

${ }^{3}$ Van Handel E, Zilversmit D B. Micromethod for the direct determination of serum triglycerides. J Lab Clin Med 1957; 50: 152-7.

4 Noble R P. Electrophoretic separation of plasma lipoproteins in agarose gel. J Lipid Res 1968; 9: 693-700.

${ }^{5}$ Morin L G. Determination of serum urate by direct $\mathrm{Fe}^{3+}$ reduction or by absorbance change (at $293 \mathrm{~nm}$ ) on oxidation of urate with alkaline ferricyanide. Clin Chem 1974; 20: 51-6.

- Bronte-Stewart B, Keys A, Brock J F. Serum-cholesterol, diet and coronary heart disease. Lancet 1955 ; ii: 1103-8.

' Slack J, Noble N, Meade T W, North W R S. Lipid and lipoprotein concentrations in 1604 men and women in working populations in north-west London. Br Med J 1977; ii: 353-7.

- Hauge M, Harvald B. Heredity in gout and hyperuricaemia. Acta Med Scand 1955; 152: 247-57.

- Darlington L G, Scott J T. Plasma lipid levels in gout. Ann Rheum Dis 1972; 31: 487-9.

10 Berkowitz D. Blood lipid and uric acid inter-relationships.JAMA 1964; 190: 856-8.

11 Frank $\mathrm{O}$. Observations concerning the incidence of disturbance of lipid and carbohydrate metabolism in gout. Adv Exp Med Biol 1974; 41: 495-8. 
12 Mielants H, Veys E M, de Weerdt A. Gout and its relation to lipid metabolism. Ann Rheum Dis 1973; 32: 501-5.

${ }^{13}$ Emmerson B T, Knowles B R. Triglyceride concentrations in primary gout and gout of chronic lead nephropathy. Metabolism 1971; 20: 721-9.

14 Gibson T, Grahame R. Gout and hyperlipidaemia. Ann Rheum Dis 1974; 33: 298-303.
15 Gibson T, Kilbourn K, Horner I, Simmonds H A. Mechanism and treatment of hypertriglyceridaemia in gout. Ann Rheum Dis 1979; 38: 31-5.

16 Darlington L G, Scott J T. Significance of alcohol in the context of hyperuricaemia and hyperlipidaemia. Unpublished data.

${ }^{17}$ Elkeles R S, Chalmers R A. Hypertriglyceridaemia and hyperuricaemia. Lancet 1977; ii: 252. 